\title{
The Impact of the Judicial Objective Function on the Enforcement of Environmental Standards ${ }^{*}$
}

\author{
Thomas Blondiau ${ }^{\mathrm{a}}$ and Sandra Rousseau ${ }^{\mathrm{b}}$ \\ ${ }^{a}$ CES, K.U. Leuven, Naamsestraat 69, B-3000 Leuven, Belgium, \\ E-mail: Thomas.Blondiau@econ.kuleuven.be \\ b CEDON, HUBrussel, Stormstraat 2, B-1000 Brussel, Belgium, \\ \& CES, K.U. Leuven, Naamsestraat 69, B-3000 Leuven, Belgium, \\ E-mail: Sandra.Rousseau@econ.kuleuven.be
}

\begin{abstract}
We investigate the influence of a judge's objective function on the type of sanctions used for enforcing environmental standards. We focus on the difference between monetary and non-monetary penalties. Therefore, we examine the extent to which judges take social costs of sanctions into account when making judgments in court in the context of environmental violations. Furthermore, we conduct an empirical analysis to test the main findings of the theoretical model using court data from several Belgian jurisdictions. We find that besides minimizing environmental damages judges also take social costs of sanctions into account in their decisionmaking.
\end{abstract}

Keywords: Environmental policy; monitoring and enforcement; non-monetary sanctions

JEL codes: K32 Environmental law; K41 Litigation process; K42 Illegal behavior and the enforcement of law; Q58 Environmental economics - government policy

\footnotetext{
* We gratefully acknowledge the financial support of the FWO project 'An economic approach to modelling the enforcement of environmental regulation' and the SBO project 060034 (www.environmental-lawforce.be). We would also like to thank Stef Proost, Carole Billiet and an anonymous referee for their useful suggestions.
} 


\section{Introduction}

The theory of regulatory enforcement lies at the crossroads of two disciplines: law and economics. When one interprets the economic view of enforcement in a judicial framework, it is apparent that both fields may yield different conclusions, simply because the objectives are different. On the one hand, economists generally argue that the basic tool of analysis is social welfare maximization and that all scarce resources need to be included in the objective function of the policy maker. This means that social costs of sanctions, such as transaction costs or fire sales due to liquidity constraints, are an indispensable part of a social welfare based cost-benefit analysis. On the other hand, enforcers with a law background are mainly concerned by making society comply with regulations. Their principal decision criterion is the deterrence effect that regulatory measures bring about. It would be unfair, however, to state that legal scholars entirely disregard efficiency aspects of sanctions. The 'proportionality principle' and the 'necessity criterion' state that sanctions should be such that the social costs for society are 'in proportion' to the seriousness of the committed violations as well as necessary to achieve the enforcement goal. At a European level, these principles are included among the legal criteria reflected in the principle of Community loyalty in Article 10 of the EC Treaty, from which the enforcement obligation of the member states derives (Meeus 2007). Still, the question to what extent deterrence and cost-effectiveness are taken into account remains to be answered. In this paper, we investigate how the trade-off between environmental and social costs affects judges' behavior in court. We develop a model to incorporate different specifications of his objective function: minimization of environmental damages only or, alternatively, minimization of all welfare costs, including both environmental damages and social costs of sanctions. We do this in a similar way as Keeler (1995) who analyzed the role of objectives in explaining the behavior of an environmental agency. He believed that in practice achieving compliance is a primary goal of the environmental regulator and that compliance costs to firms are only taken into account as a secondary concern. Our analysis, in contrast, focuses on

judicial behavior in a civil law system and we investigate the interactions between sanctions imposed by the judge and firm's emission levels.

We draw a general distinction between two types of sanctions: fines and non-monetary sanctions. Fines are generally thought to be the least costly enforcement instrument in 
terms of social welfare (Becker 1968). However, more expensive non-monetary sanctions may provide additional benefits such as the fact that imprisonment makes recidivism (temporarily) impossible or that mandatory clean up orders or (temporary) closure of a polluting firm generally lead to a cleaner environment. We show that the more important the judge deems the social costs of sanctions; the less likely it is that firms are (temporarily) closed down as a consequence of an environmental offense. Further, in an empirical analysis of Belgian court cases, we try to assess which weights are given to the deterrence effects as well as to the social costs of sanctions for environmental violations. We find that judges take both environmental effects and social costs of sanctions into account in their decision-making in Flanders (Belgium), though the exact weights could not be determined.

Imperfect compliance has been a debated topic over the last decades. The framework for the economic analysis of law breaking behavior was developed by Becker (1968). He considered law-breaking fines as equivalent to any other cost of doing business for a firm. Further, he concluded that fines have several advantages over other types of sanctions, since they require fewer productive resources and are therefore less costly to society. Afterwards, various topics related to firms' compliance decisions have been investigated ${ }^{1}$. Previous empirical studies have mainly focused on administrative sanctioning through a regulatory agency (see, e.g. Nyborg \& Telle 2006, Eckert 2004, Earnhart 1997 and Helland 2001), while the number of empirical studies on criminal sanctions is much more limited. An example in the common law tradition is Eaton et al. (2005), where the authors study the effect of seeking punitive damages on the course of tort claims at several decision points in the prosecution procedure. Our approach is more similar to Rousseau \& Billiet (2005) who analyze the fines imposed at trial in the civil law tradition, namely by the Court of Appeal in Ghent between 1990 and 2000. They determined the influence of offense and offender characteristics on the level of the penalty imposed for environmental offenses.

The economic literature on judicial decision making has been scarce for a long time. As mentioned by Posner (1993), this followed from the fact that the judicial system is designed to remove economic incentives from judges' behavior. Thus, the strategic

\footnotetext{
${ }^{1}$ For a general overview of the literature on imperfect compliance in environmental economics, we refer to Cohen (1999). Also, Polinsky \& Shavell (2000) made a comprehensive study on the welfare analysis of law enforcement. An overview of previous empirical studies on the enforcement of environmental regulations is discussed in Rousseau (forthcoming).
} 
issues involved could impair judicial objectivity. Posner (1993) was the first to state that behavior of judges can be examined using a rationality-based framework, just like analyzing the behavior of "ordinary people". Since then, a significant body of theoretical research has been developed to understand judicial behavior at a trial. For an US based overview of the 'strategic' approach to judicial decision making, we refer to Spiller \& Gely (2007). Daughety \& Reinganum (2000) model the way in which the available evidence is aggregated into a single judgment. Rasmusen (1993) and Levy (2003) developed models to investigate the importance of respecting judicial precedent in achieving legitimacy and in explaining judges' behavior. However, theoretical models of judicial objectives have only rarely been developed for judging environmental cases (for an example, see Rousseau \& Billiet 2005). Moreover, most studies previously mentioned have been developed in a common law context. It is not clear how the results concerning e.g. the importance of judicial precedence carry over to our civil law context. Fon \& Parisi (2006) state that judicial precedent can be an important component of judicial decision making in civil law countries. Its influence depends on the requirement for consistency with previous case law. However, when judges have broad discretionary freedom, the rule of precedence becomes virtually unimportant. As a case in point, judges have this type of discretionary freedom when deciding on the type and level of sanction in criminal cases in Belgium, which allows us to disregard the rule of precedence. This conclusion is corroborated by a recent study by Monsieurs et al. (2009) who surveyed Belgian judges and find that the influence of judicial precedent is indeed very limited for Belgian courts. Judges state that they sometimes $(54 \%)$ or rarely $(24 \%)$ take decisions by fellow judges into account when making sanctioning decisions.

In section II, we present the theoretical analysis of a firm-regulator interaction model. Next, in section III the empirical analysis tests the theoretical insights using trial data for environmental offenses in Flanders (Belgium). Section IV concludes.

\section{The model}

First we discuss the setup and the assumptions behind the model. Next, we address firms' compliance behavior and judges' sanctioning decisions. 


\subsection{Assumptions}

Our static model studies the firm and judicial behavior, while taking the agency's behavior as given. An exogenously given environmental standard $\bar{X}$ is in place in order to limit firm emissions $X$. Emissions are related to firm activity levels; however, firms can use abatement technology in order to emit less ${ }^{2}$. The abatement costs associated with reducing the level of emissions to $X$ are denoted by $A(X)$, with $A^{\prime}(X)<0$ and $A^{\prime \prime}(X)>0$. The level of environmental damage caused by these emissions equals $D(X)$ with $D^{\prime}(X)>0, D^{\prime \prime}(X)>0$ and $D(0)=0$. Further, we assume that the regulatory agency is perfectly informed about the marginal damage function of emissions, but imperfectly informed about firms' abatement costs. However, the regulatory agency can make an estimate about the average of these costs and the standard is set at the level which balances the average of marginal abatement costs with the marginal damage imposed on the environment. The agency monitors the standard and inspects the firm with a certain probability $P$. Since we focus on the sanctioning decision made by the judge, the environmental standard and the inspection rate are exogenously given.

In case the firm is inspected and found to violate the standard, it is brought to court. Thus, we assume that the inspection probability is equal to the prosecution probability and disregard the possibility of measurement and judicial errors. The judge decides on his sanctioning strategy depending on the extent of the violation. Hence, we define a linear penalty function (see Arguedas 2008, Rousseau \& Proost 2005, 2009):

$$
\begin{aligned}
& F=s[X-\bar{X}] \quad \text { for } \quad X-\bar{X} \geq 0 \\
& =0 \quad \text { for } \quad X-\bar{X}<0
\end{aligned}
$$

with $F^{\prime}(X-\bar{X})=s>0, F^{\prime \prime}(X-\bar{X})=0$ and with $s$ equal to the slope of the penalty function. Here, we define $F$ as the monetary equivalent of the penalty imposed and argue that for each non-monetary sanction a monetary equivalent can be found which provides firms with the same compliance incentives. Further, the sanction is limited by

\footnotetext{
${ }^{2}$ In the paper we model a representative firm and a representative judge. However, we assume that firms in the industry are heterogeneous with different production and abatement functions.
} 
the wealth $W$ of the firm, defined as the discounted value of all future incoming cash flows. Thus, we can represent the use of a warning by $F=0$ and firm closure by $F=W$.

Next, we define the function $S C(F(X-\bar{X}))$, with $S C^{\prime}(F(X-\bar{X}))>0$ and $S C^{\prime \prime}(F(X-\bar{X}))>0$, which represents the social costs entailed by the penalty imposed. We define social costs of sanctions as the sum of the burden inflicted on firms and the administrative costs for firms and government, in our case including courts and legal administrations. We assume that these social costs of sanctions increase convexly with the level of the fine, because of increasing transaction costs and more stringent liquidity constraints. Firstly, transaction costs are likely to rise because firms have higher incentives to oppose a verdict, possibly leading them to appeal the verdict, or to refuse to pay (high) fines. This leads to higher administrative costs for firms and government. Secondly, liquidity constrained firms will be hit harder by higher fines, possibly leading to fire sales, lay offs, etc. Furthermore, note that the social costs associated with firm closure vary over firms since the available wealth varies over firms.

\subsection{Firm and judicial behavior}

The model is solved using backward induction. Thus the optimal judicial sanctioning strategy takes the reaction function of firms into account. First, we determine the firm's reaction functions, before turning attention to judicial behavior.

\subsubsection{Firm behavior}

A risk-neutral firm decides on the level of emissions $X$ in order to minimize the sum of abatement costs plus the expected penalty. For a violator, the expected penalty equals the inspection probability $P$ times the penalty $F($.$) . Thus the firm's objective function$ is:

$$
\underset{X}{\operatorname{MIN}} A(X)+P \cdot F(X-\bar{X})
$$

For an interior solution, the first order condition shows that the firm's optimal level of emissions balances marginal abatement costs with marginal penalty costs:

$$
-A^{\prime}(X)=P \frac{d F(X-\bar{X})}{d X}=P \cdot s
$$


Since the marginal sanction is equal to 0 as long as the firm is in compliance and $-A^{\prime}(X)>0$ for all $X$, it is clear that the optimal emission level, denoted by $X_{0}$, is larger than or equal to $\bar{X}$ in case of an interior solution. For a corner solution, we find that $X_{0}=\bar{X}$ minimizes the firm's costs associated with the environmental regulation.

\subsubsection{Judicial behavior}

We now specify the judge's objectives when penalizing violators of the environmental standard. Rousseau (forthcoming) discusses three important, yet distinct, objective functions ${ }^{3}$ for the enforcing authority: i) social welfare maximization, ii) deterrence maximization and iii) providing justice. Firstly, social welfare maximization implies that the regulator balances compliance costs with environmental damages. Thus, an equilibrium can only be obtained if the regulator chooses a penalty that equalizes the marginal expected violation costs to the marginal damages. This social welfare maximization objective implies a harm-based approach to environmental enforcement (Polinsky and Shavell, 1994) since the sanction imposed on violators is based on the harm caused by the violation. The socially optimal sanction also optimizes deterrence since all socially detrimental violations are averted. Secondly, maximizing deterrence implies that the costs associated with violating the rules should always be larger than the cost of compliance. In this gain-based approach, the avoided compliance cost acts then as an estimate of the gain to the violator of breaking the rules. Finally, an additional objective of punishment has been to provide justice. Justice has been approached in many different ways such as procedural justice, retributive justice and restorative justice. ${ }^{4}$

Rousseau (forthcoming) concludes that the currently available empirical studies looking at the determinants of the fines imposed for environmental offenses are inadequate to capture the objectives of judges and administrations with a sufficient level of confidence. Still, some general trends emerge: fines increase with the harm caused by the offense, for repeat offenders as well as for intentional offenses. Thus, previous

\footnotetext{
${ }^{3}$ Firestone (2003) also examines these and other regulatory objectives for environmental enforcement. ${ }^{4}$ Procedural justice incorporates a theory of procedural fairness for civil dispute resolution (see Solum 2004). The concept of retributive justice is based on the principle "Let the punishment fit the crime" such that the severity of the penalty for a violation should be reasonable and proportional to the severity of the infraction (see Zaibert 2006). Restorative justice, on the other hand, is concerned with making the victim whole and reintegrating the offender into society (see Braithwaite 2002).
} 
studies provide some evidence of social welfare and justice concerns revealed by enforcers as well as a possible aversion to wrongfully convict defendants.

In Flanders the judicial objectives are formally described by Van den Wyngaert (2006). This legal scholar states that the principal objectives for a judge when penalizing violators are to protect society from harm, to show that society disapproves of certain acts and to foster recovery from the harm done. In the context of environmental offenses, these elements are mainly related to reducing environmental harm and thus with maximizing deterrence and providing justice. However, Van den Wyngaert (2006) also states that judges should bear in mind that harmful consequences of sanctions should be limited. In addition, punishments should be in proportion to damages caused by offenses and the interests of all parties involved should be respected. These requirements imply that social costs of sanctions are considered and thus welfare might be maximized. We specify a parameter $\Psi \in[0,1]$ reflecting the extent to which the judge takes the social costs of sanctions into account. We study judicial objectives for two extreme cases: $\Psi=1$ and $\Psi=0$. If $\Psi=1$, the judge behaves like a perfect welfare maximizer, taking all costs to all parties into account. If $\Psi=0$, the judge minimizes environmental harm or maximizes deterrence while ignoring the social costs of sanctions. Obviously, actual judicial behavior falls between these two extremes.

The judicial objective function consists of three terms. A first term represents the environmental damages of exceeding the standard $\bar{X}$. A second component is the social costs of a sanction. These costs increase when a more stringent penalty is imposed, until the wealth constraint of the firm is reached. A third term is the additional compliance cost, when the firm is forced to reduce emissions up to a level $\bar{X}$. The parameter $\Psi$ represents the extent to which the judge takes the second and third component into account. The judge can influence behavior by imposing a penalty $F$, subject to a firm's reaction function. The penalty increases with excess emissions $X_{0}-\bar{X}$ and with the marginal sanction $s$. Hence, the objective function is ${ }^{5}$ :

$$
\underset{s}{\operatorname{MIN}}\left\{D\left(X_{0}\right)-D(\bar{X})+\Psi\left[S C\left(F\left(X_{0}-\bar{X}\right)\right)-\left(A(\bar{X})-A\left(X_{0}\right)\right)\right]\right\}
$$

\footnotetext{
${ }^{5}$ Note that we take the level of monitoring effort as given, so monitoring activities are not included in the judicial objective function.
} 
Next we look at extreme cases for the parameter $\Psi$ by setting it equal to 0 or 1 , since their analysis is useful as a benchmark.

Case a: $\Psi=1$

In this scenario, the judge's objective function includes all welfare costs associated with environmental violations and imposing sanctions. Since the firm's emission level equals $X_{0}$, the objective function is:

$$
\underset{s}{\operatorname{MIN}} D\left(X_{0}\right)-D(\bar{X})+\left[S C\left(F^{\Psi=1}\left(X_{0}-\bar{X}\right)\right)-\left(A(\bar{X})-A\left(X_{0}\right)\right)\right]
$$

Defining the optimal marginal penalty when $\Psi=1$ as $s^{*}$, the first order condition determining the optimal penalty $F^{\Psi=1}()=.s *\left[X_{o}-\bar{X}\right]$ is:

$$
S C^{\prime}(F(s)) F^{\prime}(s)=-X_{0}{ }^{\prime}(s)\left[D^{\prime}\left(X_{0}(s)\right)+A^{\prime}\left(X_{0}(s)\right)\right]
$$

Thus, the optimal marginal penalty balances marginal costs and marginal benefits of increasing the sanction. A rise of the marginal sanction $s$ increases firm's abatement efforts and thus decreases emissions, as shown in expression (1). The decreasing emissions have counteracting effects on damages and abatement costs and the overall impact depends on the initial amount emitted.

Now we discuss when it is rational to impose a warning or to close a firm. Previously, we stated that these non-monetary sanctions are equivalent to imposing a zero fine (warning) or a fine equal to the firm's entire wealth (firm closure). Thus it is optimal to impose a warning, if the marginal social costs of sanctions exceed the marginal benefits at all levels of $s$. This would be the case if marginal environmental damages are low, abatement costs for firms are high or marginal social costs of sanctions are high. In contrast, if marginal benefits of sanctioning are above marginal social sanctioning costs for all $s$, permanently closing down the firm becomes the appropriate sanction. Thus smaller firms face a higher risk of being closed down, because their wealth constraint is more often binding.

Case b: $\Psi=0$

The judge's objective function simplifies considerably when $\Psi=0$ and becomes: 


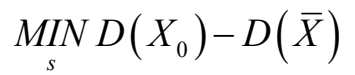

The first order condition for the marginal fine $s$ is then:

$$
D^{\prime}\left(X_{0}(s)\right) \cdot X_{0}{ }^{\prime}(s)=0
$$

We know that $D^{\prime}()>$.0 for all $X$ and that $X_{0}{ }^{\prime}(s)<0$ in case of an interior solution for the firm's problem. Hence, the solution to the judge's minimization problem is to set the marginal fine sufficiently high to encourage all firms to comply, inducing a corner solution to the firm's cost minimization problem. However, since firms' abatement cost functions are imperfectly known, a judge who wants to deter all possible violations has to impose a fine equal to the entire wealth of the firm, i.e. to close down all violating firms. So, in this extreme case, we find that $F^{\Psi=0}=W$ for $X>\bar{X}$ and $F^{\Psi=0}=0$ for $X \leq \bar{X}$, with $F^{\Psi=0}($.$) representing the optimal penalty when \Psi=0$. Thus, a judge who mostly cares about deterrence will impose more stringent sanctions than a judge who takes all welfare costs into account. Also, firms are closed down more often when the social costs of sanctions have little influence on the judicial decision.

\subsection{Summary of the theoretical analysis}

The theoretical analysis allows us to formulate testable hypotheses for the empirical analysis. Importantly, a deterrence maximizing judge is expected to be more severe and to impose more stringent sanctions for the same violation than a welfare maximizing judge. Further, the more a judge cares about the deterrence effect of sanctions, the more often the judge will close down offending firms. Also, a welfare maximizing judge might close down smaller firms more easily than larger firms, due to the effect of the wealth constraint. This last observation holds for all values of $\Psi$ except at the corner case $\Psi=0$, in which case the judge would close down every violator. Thus we have:

Hypothesis 1: A judge closes larger firms less often than smaller firms, if the judge takes the social costs of sanctions - to some extent - into account.

Further, environmental damages are part of the objective functions for the welfare maximizing as well as the deterrence maximizing judge. This gives us: 
Hypothesis 2: The stringency of sanctions is positively related to the seriousness of environmental damages.

One can see that these hypotheses are related to the goal of achieving deterrence (hypothesis 2) in an efficient way (hypothesis 1). Finally, under specific circumstances, it may be optimal for a judge to impose a warning rather than imposing an actual sanction. Again, this conclusion holds for all values of $\Psi$ except when $\Psi=0$.

\section{Empirical analysis}

In this section, we test the hypotheses formulated in section 2.3 on environmental cases criminally prosecuted between 2003 and 2006 in Flanders (Belgium). First, we describe the dataset. Next, we discuss the estimation method and outline expected results.

\subsection{Data}

The database contains information on criminal sanctions for environmental violations imposed by the Courts of First Instance between 2003 and 2006 in seven judicial districts of the Flemish region in Belgium ${ }^{6}$. We restrict ourselves to cases where the accused was a firm (excluding natural persons). Thus, we have 175 usable observations.

We distinguish two dependent variables: NSANCTION and (LN)FINE. Firstly, the dummy variable NSANCTION indicates whether a non-monetary sanction was imposed and is equal to one if the offending firm was closed or if the damages caused had to be cleaned up by the offender. So the variable NSANCTION can be further decomposed into a variable representing (temporary) firm CLOSURE and one indicating a mandatory CLEANUP requirement. Secondly, the variable FINE equals the imposed monetary penalty. Since its distribution is strongly skewed to the right, a logarithmic transformation is applied to this variable, which is denoted LNFINE. Summary statistics of the dependent variables are given in Table I.

The judge's choice of the type of sanction (monetary versus non-monetary) was shown to depend on the sanction's impact on environmental quality, on the social costs of sanctions and on firms' abatement costs $(D, S C$ and $A)$. Moreover, the level of the

\footnotetext{
${ }^{6}$ More information on the design of the database can be found in Billiet et al. (2009).
} 
monetary sanction was determined by the seriousness of the violation, $(X-\bar{X})$. Thus, we need proxies for these factors in order to perform the regressions explaining NSANCTION and LNFINE.

\begin{tabular}{|l|c|c|c|c|}
\hline Variable & Mean & Std. Dev. & Minimum & Maximum \\
\hline FINE & $€ 15210$ & $€ 50681$ & $€ 275$ & $€ 500000$ \\
LNFINE & 8,37 & 1,33 & 5,62 & 13,12 \\
\hline Dummy variable & & Frequency 0 & Frequency 1 \\
\hline NSANCTION & & 138 & 37 \\
CLOSURE & & 153 & 22 \\
CLEANUP & & 157 & 18 \\
\hline
\end{tabular}

Table I: Summary statistics of dependent variables

Firstly, it is hard to find data to measure the social costs of sanctions in an exact way. Therefore, we approximate the defendant's economic importance by the total assets (in $1000 €)$ on its balance sheet at the end of the year before the judgment was made. The logarithmic transformation of this variable is called LNASSETS. Thus we can test hypothesis 1 and check whether larger firms have a smaller probability of being closed down than smaller firms, ceteris paribus. Secondly, we look at the seriousness of environmental damage caused by the violation. The variable COMMUNITY indicates whether the damages had a significant impact on the surrounding community. It takes a value of 1 if the offense had a negative impact on the health of a third party or on somebody's property, if public health was affected, if vulnerable areas were damaged or if living species were negatively affected. The dummy variable MULTIPLE takes a value of 1 if the defendant is being judged for offending several regulations in the same case. Summary statistics of these explanatory variables are provided in Table II.

Next, to control for the characteristics of the violation, we introduce variables that reflect the type of environmental damage caused: problems with WASTE disposal, NOISE nuisance, SOIL, surface WATER and ODOR/AIR contamination. The reference category is given by offenses where no direct contamination was caused, or where no information on the type of contamination was available. We also indicate whether a POSITIVE action was taken by the defendant to limit environmental damages. The 
defendant's sector of activity is included as an additional control variable. We define sectoral dummies for firms active in the PRIMARY sector (i.e. mainly agriculture) and for firms active in the TERTIAIRY sector (i.e. services). In addition, we check whether the defendant has committed offenses previous to the current trial. If this is the case, the dummy variable HISTORY takes a value of 1 .

\begin{tabular}{|l|c|c|c|c|}
\hline Variable & Mean & Std. Dev. & Minimum & Maximum \\
\hline ASSETS (1000€) & $€ 8864$ & $€ 29236$ & $€ 1$ & $€ 319000$ \\
LNASSETS & 6,77 & 2,33 & 0 & 12,67 \\
\hline Dummy variable & & Frequency 0 & Frequency 1 \\
\hline COMMUNITY & & 146 & 29 \\
MULTIPLE & & 62 & 113 \\
\hline
\end{tabular}

Table II: Summary statistics of most important explanatory variables

Finally, we introduce time dummies (Y04, Y05 and Y06) to control for time trends in our database (reference year is 2003). We also use a regional control variable URBAN which equals 1 if the particular case is tried at the court of Ghent, the main urban area in our database. Table III summarizes the frequencies of the control variables.

\begin{tabular}{|l|c|c|c|c|c|}
\hline Dummy variable & $\begin{array}{c}\text { Frequency } \\
0\end{array}$ & $\begin{array}{c}\text { Frequency } \\
1\end{array}$ & Dummy variable & $\begin{array}{c}\text { Frequency } \\
0\end{array}$ & $\begin{array}{c}\text { Frequency } \\
1\end{array}$ \\
\hline WASTE & 117 & 58 & PRIMARY & 145 & 30 \\
NOISE & 119 & 56 & TERTIARY & 111 & 64 \\
SOIL & 154 & 21 & HISTORY & 165 & 10 \\
WATER & 153 & 22 & URBAN & 104 & 71 \\
ODOR/AIR & 151 & 24 & Y04 & 144 & 31 \\
POSITIVE & 121 & 54 & Y05 & 126 & 49 \\
& & & Y06 & 117 & 58 \\
\hline
\end{tabular}

Table III: Summary table with frequency of occurrence of the control variables 


\subsection{Estimation method and expected results}

We first estimate ${ }^{7}$ a probit model to explain the probability that a non-monetary sanction (NSANCTION) is imposed. Next, we estimate the factors determining the fine (LNFINE), once using OLS and once after introduction of an additional term (i.e. the inverse mills ratio) to control for sample selection bias $^{8}$. The fine levels are estimated separately for the cases with a non-monetary sanction and for the cases without nonmonetary sanction. The average fine imposed on defendants which do not receive a nonmonetary sanction is $€ 12$ 166, with a standard deviation of 45010 . The average fine imposed on defendants which did receive a non-monetary sanction, in contrast, is equal to $€ 24082$, with a standard deviation of 62 096. These different fine levels indicate that a selection bias might be present. If this bias can be explained by (some of the) observable explanatory variables, no correction through the additional term is necessary. If the selection is based on unobservable characteristics, however, we should include the Inverse Mills Ratio to control for the sample selection effect. We compare the estimated coefficients resulting from both approaches in Table V. The estimation of fine levels mainly focuses on firms that did not receive a non-monetary sanction, because the stringency of their total sanction is directly related to the imposed fine. For firms that faced a non-monetary sanction combined with a fine, the monetary sanction imposed is only one component of the total sanction. Thus, interpretation of the effect of the explanatory variables on the level of the total sanction is less straightforward.

The empirical analysis can be used to comment on the two hypotheses related to the cost-efficiency of penalties and to their deterrence effect. If social costs of sanctions are taken into account, hypothesis 1 applies. We expect that the variable LNASSETS enters the estimated probit model with a negative coefficient, because closure of larger firms is costlier for society than that of smaller firms. In contrast, we expect a positive coefficient for LNASSET in the fine estimation, because larger firms operate on a larger scale and thus, for an equal marginal penalty, larger firms on average incur higher monetary fines. From the second hypothesis it follows that the variables COMMUNITY and MULTIPLE should have a positive effect both on the sanctioning probability and on the fine. In addition, a negative compliance HISTORY should lead to more stringent

\footnotetext{
${ }^{7}$ All estimations are executed using the statistical software package LIMDEP.

${ }^{8}$ Following the approach proposed by Heckman (1979), we should include an additional term, called the inverse mills ratio, into the estimated linear models to obtain consistently estimated coefficients in the presence of sample selection bias.
} 
sanctions since higher sanctions might be needed in order to make repeat offenders compliant. Since POSITIVE actions taken by offenders reduce the environmental damages, we expect less stringent penalties in these instances.

\subsection{Results}

First, we estimate a probit model to study the probability that a non-monetary sanction is imposed. Next, a linear model is estimated to identify the factors determining fines.

\subsubsection{Probability of non-monetary sanction}

Table IV presents the estimation of the probability that a non-monetary sanction is imposed. The results with NSANCTION as the dependent variable are given in the second column of Table IV. However, the non-monetary sanctions actually consist of firm closures (CLOSURE) as well as recovery requirements (CLEANUP). Therefore, we estimate two additional models with CLOSURE and CLEANUP as separate dependent variables. Due to the limited number of occurrences for these dependent variables, fewer explanatory variables are included. Thus, we see that the predictive power $^{9}$ of the first model exceeds that of the second or third model.

\begin{tabular}{|l|c|c|c|c|}
\hline \multicolumn{5}{|l|}{ Binomial Probit model: Y $=$ PROB(Dep. Var.=1|X) } \\
\hline \# Obs $=175$ & $-0,50(0,61)$ & $-0,63(0,44)$ & $-\mathbf{2 , 4 1}(\mathbf{0 , 7 0})^{* * *}$ & \\
\hline Dependent Variable & NSANCTION & CLOSURE & CLEANUP & Exp \\
\hline Constant & $-0,06(0,32)$ & & & \\
URBAN & $-0,14(0,43)$ & & & \\
PRIMARY & $-0,51(0,37)$ & & $0,003(0,58)$ & + \\
TERTIAIRY & $\mathbf{0 , 9 3 ( \mathbf { 0 , 3 9 } ) * *}$ & $\mathbf{0 , 6 9 ( 0 , 3 2 ) * *}$ & $-0,39(0,72)$ & + \\
COMMUNITY & $0,24(0,51)$ & $0,40(0,53)$ & $0,45(0,36)$ & + \\
HISTORY & $0,35(0,26)$ & $0,37(0,29)$ & $\mathbf{1 , 6 8 ( 0 , 3 8 ) * * *}$ & \\
MULTIPLE & $\mathbf{0 , 8 9 ( 0 , 3 1 ) * * *}$ & $0,33(0,30)$ & & \\
WASTE & $-0,27(0,48)$ & & & \\
NOISE & $-0,28(0,45)$ & & & \\
SOIL & & & & \\
\end{tabular}

\footnotetext{
9 Note that the threshold level for predicting an outcome $=1$ is set at 0,35 for the estimation of NSANCTION, in accordance with the low share (i.e. $21,4 \%$ ) of occurrences for NSANCTION. For the other two models the threshold level is set at 0,3 in accordance with shares of $12,57 \%$ and $10,28 \%$.
} 


\begin{tabular}{|c|c|c|c|c|}
\hline POSITIVE & $-1,19(0,35) * * *$ & $-0,94(0,39)^{* *}$ & $-0,85(0,39) * *$ & - \\
\hline LNASSETS & $-0,14(0,07)^{* *}$ & $-0,13(0,06)^{* *}$ & $0,015(0,08)$ & - \\
\hline Y04 & $0,40(0,44)$ & & & \\
\hline Y05 & $0,54(0,40)$ & & & \\
\hline Y06 & $0,67(0,39)^{*}$ & & & \\
\hline $\begin{array}{l}\text { \% Correct predictions } \\
\text { (benchmark: regression } \\
\text { with a constant term only) }\end{array}$ & $82,3 \%(78,9 \%)$ & $86,3 \%(87,4 \%)$ & $88 \%(89,7 \%)$ & \\
\hline$\%$ Correct pred actual 0 & $90 \%(100 \%)$ & $96 \%(100 \%)$ & $92 \%(100 \%)$ & \\
\hline$\%$ Correct pred actual 1 & $54 \%(0 \%)$ & $18 \%(0 \%)$ & $50 \%(0 \%)$ & \\
\hline McFadden pseudo $\mathrm{R}^{2}$ & 0,23 & 0,13 & 0,29 & \\
\hline
\end{tabular}

Estimated coefficients are given without brackets, standard errors between brackets

* indicates significance at $10 \%$ level, ** at $5 \%$ level and *** at $1 \%$ level

Table IV: Output of the estimation of the non-monetary sanction probability

We now discuss the estimated coefficients. First, we focus on the results of the regression for NSANCTION (second column, table IV). We investigate hypothesis 1 by looking at our proxy for the social costs of imposing a non-monetary sanction. Larger firms (LNASSETS) have a significantly lower probability of receiving a non-monetary sanction. More specifically, as indicated by the significant (5\%) coefficient in the third column, we find that larger firms have a significantly lower probability of being (temporarily) closed down. Thus, the results provide evidence in support of the hypothesis that larger (or, economically more important) firms have a lower probability of being closed down as a sanction for an environmental offense compared to smaller firms. This result also indicates that judges take social costs of sanctions into account when deciding on the type of sanction and do not only focus on deterrence. Calculating the marginal effect ${ }^{10}$ of LNASSETS, we find that a $1 \%$ increase in the size of the firm (expressed in 1000€) leads to an average decrease of 0,033 percentage points in the probability that a non-monetary sanction is imposed. This decrease may seem small, but given the wide range of firm assets, the size effect could lead to significant differences in the probability of receiving a non-monetary sanction in our database.

To assess the magnitude of the size effect on the probability of imposing a nonmonetary sanction, we let the variable LNASSETS range from its minimum 0 to its maximum value 12,67 , holding the other variables fixed at their means. The resulting probability of imposing a non-monetary sanction ranges from as high as 0,45 down to

\footnotetext{
${ }^{10}$ The marginal effect of a variable represents the effect of a one unit increase in an explanatory variable on the dependent variable, evaluated at the mean of the other explanatory variables.
} 
about 0,04 . Thus, the level of firm ASSETS seems to be a significant component in the judicial decision to impose a non-monetary sanction.

Next, we look at the variables representing the seriousness of the violation. We find that violations that caused noticeable damage to properties, health, or natural resources (COMMUNITY) have a significantly higher probability of receiving a non-monetary sanction. The significance of this community coefficient is mainly attributed to its impact on firm CLOSURE. When the offense had an impact on the surrounding community, the partial effect implies an increase in the probability of receiving a nonmonetary penalty by 28 percentage points. This result provides support for the second hypothesis, i.e. the likelihood of receiving a penalty is higher for cases where environmental damages are more important and/or where they are more visible since they affect the community. Therefore, HISTORY and MULTIPLE were also expected to have a positive impact on the sanctioning probability. Their estimated coefficients have the right (positive) sign, but they are not statistically significant. The nonsignificance of HISTORY might indicate that the environmental characteristics of a violation are more important to induce a judge to impose a non-monetary sanction than the violator's culpability.

Furthermore, a POSITIVE action taken to mitigate environmental damages has a significantly negative effect on the probability of receiving a non-monetary sanction, be it a (temporary) firm closure or a mandatory cleanup requirement. The partial effect of this variable indicates a decrease in the probability of imposing a non-monetary sanction of 21 percentage points. We also find increases in non-monetary sanction probabilities over time, with a significant coefficient for Y2006. The sectorial dummies do not seem to influence the probability of receiving a non-monetary sanction.

Finally, we find that WASTE-related violations have a significantly higher probability of receiving a non-monetary sanction, with a partial effect of 23 percentage points. This effect can mainly be attributed to the positive impact of a CLEANUP requirement on damages caused. This makes sense since illegal waste disposal naturally leads to clean up requirements, while this is less likely for other types of offenses. 


\subsubsection{The level of the fine}

After estimating the probability of imposing a non-monetary sanction, we turn to the regression of the level of the monetary sanction imposed. First, following the Heckman framework, the estimation of the dependent variable LNFINE is executed by adding the inverse mills ratio IMR as an additional explanatory variable to correct for a possible sample selection bias. LNFINE is estimated separately for the group of defendants that were fined without an additional non-monetary sanction and for those that were fined and also received a non-monetary sanction. As a robustness check and since the estimated coefficient of IMR is not significant, we also estimate a linear model without making the sample selection correction. The results are given in Table V.

\begin{tabular}{|c|c|c|c|c|c|}
\hline \multicolumn{6}{|c|}{ Linear model with LNFINE as the dependent variable } \\
\hline \multirow{2}{*}{\begin{tabular}{|l}
$\#$ Obs \\
Models
\end{tabular}} & \multirow{2}{*}{$\begin{array}{c}138 \\
\text { Sample selection for } \\
\text { NSANCTION }=0\end{array}$} & \multicolumn{2}{|c|}{37} & \multicolumn{2}{|l|}{175} \\
\hline & & \multicolumn{2}{|c|}{$\begin{array}{l}\text { Sample selection for } \\
\text { NSANCTION }=1\end{array}$} & Linear model & Exp \\
\hline Variable & Coef. & Coef. & Part. Effect & Coef. & \\
\hline Constant & $6,98(0,49)^{* * *}$ & $3,97(2,29)$ & & $6,66(0,37)^{* * *}$ & \\
\hline URBAN & $1,30(0,19) * * *$ & $1,09(0,75)^{*}$ & $1,21(0,97)$ & $1,38(0,19) * * *$ & \\
\hline PRIMARY & $0,27(0,25)$ & $1,04(1,13)$ & & $0,36(0,25)$ & \\
\hline TERTIAIRY & $-0,29(0,26)$ & & & $-0,19(0,22)$ & \\
\hline COMMUNITY & $0,16(0,30)$ & $1,96(1,17)^{*}$ & $0,18(1,81)$ & $0,25(0,25)$ & + \\
\hline HISTORY & $-0,38(0,39)$ & $2,92(1,22) * *$ & $2,46(1,59)$ & $0,53(0,36)$ & + \\
\hline MULTIPLE & $0,30(0,19)$ & $0,67(0,78)$ & & $0,31(0,17)^{*}$ & + \\
\hline WASTE & $0,10(0,31)$ & $2,36(1,36)^{*}$ & $0,65(1,85)$ & $0,32(0,20)$ & \\
\hline NOISE & $0,01(0,23)$ & & & $0,16(0,24)$ & \\
\hline SOIL & $-0,41(0,28)$ & & & $-0,38(0,27)$ & \\
\hline POSITIVE & $-0,78(0,27) * * *$ & $-2,21(1,43)$ & & $-0,61(0,18) * * *$ & - \\
\hline LNASSETS & $0,15(0,05)^{* * *}$ & $-0,07(0,21)$ & & $0,15(0,04)^{* * *}$ & + \\
\hline Y04 & & & & $-0,09(0,26)$ & \\
\hline Y05 & & & & $0,24(0,23)$ & \\
\hline Y06 & & & & $-0,36(0,24)$ & \\
\hline IMR & $0,37(0,64)$ & $2,37(1,53)$ & & & \\
\hline $\operatorname{Adj} R^{2}$ & 0,40 & & & 0,392 & \\
\hline
\end{tabular}

Estimated coefficients are given without brackets, standard errors in between brackets

* indicates significance at $10 \%$ level, ** at $5 \%$ level and *** at $1 \%$ level

Table V: Output of the regression of the level of the sanction imposed 
We first focus on the results of the sample selection models ${ }^{11}$. For the group of defendants without non-monetary sanction, fines are significantly higher for firms located in urban surroundings (URBAN) and for larger firms (LNASSETS), while fines significantly decrease for firms that took positive mitigating actions (POSITIVE). As expected, taking a POSITIVE action to mitigate environmental damages makes the level of the fine decrease significantly (at $5 \%$ level). The partial effect ${ }^{12}$ of POSITIVE indicates that firms that take positive actions can expect a 54\% lower fine. The estimated effect of a $1 \%$ increase in the firm's ASSETS is a $0,15 \%$ increase in the fine level. So it seems that larger firms, besides facing a marginal decrease in probability of being sanctioned non-monetarily, also face a considerable increase in the expected level of their fine. This increase might reflect that firms operating on a larger scale automatically cause larger environmental damages than smaller firms. So for the same per unit fine, they incur higher total fines. Finally, we found that expected fines imposed in an URBAN area (i.e. in the judicial district of Ghent) are, ceteris paribus, $267 \%$ higher than those imposed in other, more rural areas. Because we control for the community impact of offenses, for sectoral differences and for differences concerning the type of contamination, we believe that this effect can mainly be attributed to particular judicial objectives in the district of Ghent. It seems that the court in this area has a higher preference for environmental damage minimization and is less sensitive to the social costs of sanctions compared to other courts. In terms of our model, the results indicate that at the court of Ghent the parameter $\Psi$ in the judicial objective function is closer to zero than at the other courts.

In contrast to our expectations, offenders who were previously convicted (HISTORY) or were prosecuted for multiple violations (MULTIPLE) did not receive a higher fine for the group of defendants without a non-monetary sanction. However, HISTORY is significant for defendants that incurred a non-monetary sanction as well as a fine. So, repeat offenders who received a non-monetary sanction face higher fines. It could be that recidivism is interpreted as a signal of intentional non-compliance and that therefore more stringent sanctions as well as additional non-monetary sanctions are

\footnotetext{
${ }^{11}$ The time effects were not significant in the sample selection models.

${ }^{12} \mathrm{We}$ are looking at changes in dummy variables. Thus, the interpretation of a change in a logarithmic variable as a percentage change is no longer a good approximation since the partial changes for dummies (from 0 to 1 ) are large. Thus the partial effects are calculated as: $100\left(e^{\text {COEF }}-1\right)$ (Wooldridge, 2006).
} 
required if judges wish to make them comply. Offending MULTIPLE regulations has the correct (positive) sign in the sample selection models and is also statistically significant in the linear regression model. This indicates that multiple offenders might be punished more severely.

In the sample selection model for offenders who were punished non-monetarily, we also find that URBAN and WASTE have a significantly positive effect on the level of the fine. The estimated partial effect of the variable WASTE, however, is not significant. So its significant coefficient should probably be attributed to the sampling effect. In the linear model, fines again increase with the size of the firm and for firms located in the city of Ghent and decrease when firms take remedial actions. Furthermore, fines are higher for MULTIPLE offenders. Thus, we can conclude that the significance of these three coefficients is quite robust over model specifications.

\subsection{Scenario exercise}

We now assess how the probability that a non-monetary sanction is imposed varies with economic importance of the firm, represented by his amount of ASSETS. We do this exercise for different combinations of the other variables that we identified as determinants for imposing a non-monetary sanction: COMMUNITY, WASTE and POSTIVE. Table VI provides an overview of the results.

\begin{tabular}{|l|l|l|l|l|l|l|}
\hline ASSETS (in 1000€) & 1000 & 2000 & 4000 & 8000 & 16000 & 32000 \\
\hline $\begin{array}{l}\text { COMMUNITY }=1 \\
\text { WASTE }=1 \\
\text { POSITIVE }=1\end{array}$ & 0,354 & 0,319 & 0,286 & 0,255 & 0,225 & 0,198 \\
\hline $\begin{array}{l}\text { COMMUNITY }=1 \\
\text { WASTE }=1 \\
\text { POSITIVE }=0\end{array}$ & 0,764 & 0,734 & 0,701 & 0,668 & 0,632 & 0,596 \\
\hline $\begin{array}{l}\text { COMMUNITY }=1 \\
\text { WASTE }=0 \\
\text { POSITIVE }=1\end{array}$ & 0,091 & 0,076 & 0,064 & 0,053 & 0,043 & 0,035 \\
\hline $\begin{array}{l}\text { COMMUNITY }=0 \\
\text { WASTE }=1 \\
\text { POSITIVE }=1\end{array}$ & 0,095 & 0,08 & 0,067 & 0,055 & 0,045 & 0,037 \\
\hline
\end{tabular}

Table VI Sensitivity analysis for non-monetary sanction probability with respect to firm assets 
In the first two rows of Table VI we find that a $100 \%$ increase in ASSETS leads to a decrease in the non-monetary sanction probability which is not far from 3,3 percentage points. This is the equivalent to the marginal decrease of 0,033 for a $1 \%$ increase in ASSETS that we estimated in section 3.3.1. It is only when the non-monetary sanction probabilities are much lower, such as in the third and fourth row of Table VI, that the marginal effect of firm ASSETS on these probabilities become less important.

\subsection{Summary of the empirical analysis}

To summarize our empirical findings, we find support for the first and the second hypothesis formulated in section II. In support of the first hypothesis, larger firms are found to be closed down less frequently than smaller firms. This strengthens the view that courts balance the deterrence effect of sanctions on future violations with the social costs of using a particular sanction before reaching a verdict. So, in our illustration the case that $\Psi=0$ can be excluded. In support of the second hypothesis, violations that have a considerable impact on the community have a significantly higher chance of being penalized in a non-monetary way. Also, measures taken to limit environmental damages reduce the probability that a non-monetary sanction is imposed on the offender as well as the level of the imposed fine. Furthermore, offenders with a negative compliance history seem to incur significantly higher fines if they simultaneously received a non-monetary sanction. These findings support the view that environmental damages, and thus the seriousness of the violations, are indeed important drivers of the stringency of sanctions.

From our results, it seems that intentionality of defendants, as signaled through their compliance history and their willingness to take actions to mitigate damages, is an important determinant of the level of the penalty. In contrast, the decision to impose a non-monetary sanction is influenced by the consequences of a violation such as the impact on the community. In our case, the multiplicity of committed violations does not look like a very important component, although we found some evidence that offenders of multiple regulations face higher penalties. Possibly, judges prefer to focus on the intentionality of the offense and on the most serious of the different violations rather than the number of violated regulations. Finally, the empirical analysis also indicates that judges at the court in Ghent, the main urban area in our dataset, are more averse to 
firms imposing environmental damages on society and are less concerned by the social costs of sanctions than the judges at other Flemish courts in our dataset.

\section{Conclusion}

Our principal objective was to investigate whether judges balance environmental costs with social costs of sanctions when making their judgments or whether they solely focus on deterrence. Indeed, we observe that the economic and the judicial view on regulatory enforcement may lead to different objectives and therefore to different enforcement strategies. First, we developed a theoretical model to analyze judicial objectives subject to firm behavior. We solve the model under two benchmark scenarios for the judge's objectives corresponding to a judge behaving as a social welfare maximizer and to a judge maximizing deterrence for committing environmental offenses. We observe that a welfare maximizing judge has a rationale for imposing (temporary) closure as a sanction when firms are wealth constrained. In addition, we found that the less important the judge deems the social costs of sanctions, the more often these sanctions will be imposed. To enhance the realism of this model, a multi-period model could be developed to introduce the possibility of penalty leverage if infringements occur repeatedly at the same firm. Another extension could be to introduce settlement mechanisms and measurement errors into the model.

From the empirical analysis, we learned that social costs of sanctions and the extent of environmental damages are both elements taken into consideration when deciding on the penalty to impose. We observe that larger firms are closed down significantly less often than smaller firms. In addition, we found an indication that judicial objectives at the court in Ghent are more inclined towards preventing environmental damage, in comparison with other courts in the dataset. A possible extension could be to use more specific data on the environmental costs of violations and on the social costs of sanctions in order to analyze more precisely the extent to which both elements are taken into account by judges.

\section{References}

Arguedas C. (2008). To comply or not to comply? Pollution standard setting under costly monitoring and sanctioning. Environmental and Resource Economics, 41(2), 155-168. 
Becker G.S. (1968). Crime and punishment: An economic approach. Journal of Political Economy, 76(2), 169-217.

Billiet C.M., Rousseau S., Balcaen A., Meeus R., Styns K., De Meyer G., Vander Beken T. \& Lavrysen L. (2009). Milieurechtshandhaving: Een databank voor onderzoek naar de penale en bestuurlijke santioneringspraktijk. Tijdschrift voor Milieurecht, 18(2), 128150 .

Braithwaite J. (2002). Restorative justice and responsive regulation. Oxford University Press.

Cohen M.A. (1999). Monitoring and enforcement of environmental policy. In T. Tietenberg \& H. Folmer (eds.), International yearbook of environmental and resource economist, volume III (pp.44-106). Cheltenham UK, Edward Elgar Publishers.

Daughety A.F. \& Reinganum J.F. (2000). On the economics of trials: adversarial process, evidence and equilibrium bias. Journal of Law, Economics and Organization, 16(2), 365-394.

Earnhart D. (1997). Enforcement of environmental protection laws under communism and democracy. Journal of Law and Economics, 40, 377-402.

Eaton T.A., Mustard D.B. \& Talarico S.M. (2005). The effects of seeking punitive damages in the processing of tort claims. Journal of Legal Studies, 34, 343-369.

Eckert H. (2004). Inspections, warnings and compliance: the case of petroleum storage regulation. Journal of Environmental Economics and Management, 47, 232-259.

Firestone J. (2003). Enforcement of pollution laws and regulations: An analysis of forum choice. Harvard Environmental Law Review, 27, 105-176.

Fon V. and Parisi F. (2006). Judicial precedents in civil law systems: A dynamic analysis. International Review of Law \& Economics, 26, 519-535.

Heckman J. (1979). Sample selection bias as a specification error. Econometrica, 47, 153-161.

Helland E. (2001). Prosecutorial discretion at the EPA: Some evidence on litigation strategy. Journal of Regulatory Economics, 19(3), 271-294.

Keeler A.G. (1995). Regulatory objectives and enforcement behavior. Environmental and Resource Economics, 6, 73-85.

Levy G. (2003). Careerist judges and the appeals process. RAND Journal of Economics, $36(2), 275-297$.

Meeus R. (2007). De handhavingsplicht van de lidstaten van de Europese Unie in het communautair milieurecht, Tijdschrift voor Milieurecht, 6, 311-359. 
Monsieurs A., Rozie J. \& Vanderhallen M. (2009). Consistenten bestraffing: utopie of realiteit? Rechtskundig weekblad, 10, 90-103.

Nyborg K. \& Telle K. (2006). A dissolving paradox: Firms' compliance to environmental regulation. Environmental and Resource Economics, 35(1), 1-18.

Polinsky A.M. \& Shavell S. (1994). Should liability be based on the harm to the victim or the gain to the injurer? Journal of Law, Economics and Organization, 10, 427-437

Polinsky A.M. \& Shavell S. (2000). The economic theory of public enforcement of law. Journal of Political Economy, 102(5), 1039-1066.

Posner R.A. (1993). What do judges maximize? (The same thing everybody else does.) Supreme Court Economic Review, 3, 1-41.

Rasmussen E. (1994). Judicial legitimacy as a repeated game. Journal of Law, Economics, and Organization, 10, 68-83.

Rousseau S. (forthcoming). Empirical analysis of sanctions for environmental violations. International Review of Environmental and Resource Economics. (Doi:10.1561/101.00000024)

Rousseau S. \& Billiet C.M. (2005). How to determine fining behavior in court? Game theoretical and empirical analysis. ETE Working Paper Series, N2005-10.

Rousseau S. \& Proost S. (2005). Comparing environmental policy instruments in the presence of imperfect compliance - a case study. Environmental and Resource Economics, 32(3), 337-365.

Rousseau S. \& Proost S. (2009). Relative cost efficiency of market-based environmental policy instruments with imperfect compliance. International Tax and Public Finance, $16(1), 25-42$.

Solum L.B. (2004). Procedural justice. Southern California Law Review, vol. 78, p191322.

Spiller P.T. \& Gely R. (2007). Strategic judicial decision making. NBER Working Paper Series, N13321.

Van den Wyngaert C. (2006). Strafrecht, Strafprocesrecht \& Internationaal Strafrecht. Maklu, p432.

Wooldrigde J.M. (2006). Introductory Econometrics: A Modern Approach. Thomson South Western, p238.

Zaibert L. (2006). Punishment and retribution. Ashgate Publishing. 